\title{
Basaloid Squamous Cell Carcinoma of the Lung Associated With Syndrome of Inappropriate Antidiuretic Hormone Secretion
}

\author{
Ashraf Abugroun ${ }^{\mathrm{a}, \mathrm{b}}$, Fatima Ahmed ${ }^{\mathrm{a}}$, Toni-Denise Espina ${ }^{\mathrm{a}}$, Alvaro Altamirano Ufion ${ }^{\mathrm{a}}$
}

\begin{abstract}
Basaloid squamous cell carcinoma (BSQCC) of the lung is a very rare subtype of squamous cell carcinoma (SCC). There have been no reported cases of syndrome of inappropriate anti-diuretic hormone secretion (SIADH) developing concurrently with this tumor. We herein present a case of a 68 -year-old female who was diagnosed with lung mass discovered incidentally on preoperative clearance for surgical fixation of right humeral neck fracture. The patient presented to the hospital with nausea, vomiting, diarrhea and fatigue. Sodium level on admission was $115 \mathrm{mmol} / \mathrm{L}$. Further workup confirmed a diagnosis of BSQCC of the lung and SIADH.
\end{abstract}

Keywords: SIADH; Basaloid squamous cell carcinoma

\section{Introduction}

Syndrome of inappropriate anti-diuretic hormone secretion (SIADH) was first reported by Schwartz et al in 1957 describing two patients with lung cancer who developed hyponatremia with persistent urinary sodium loss [1]. A wide range of malignant tumors has been reported to cause SIADH. Among lung tumors, it is particularly associated with small cell lung cancer (SCLC) and in very few cases, in association with nonsmall cell lung cancer (NSCLC) [2-5]. Basaloid squamous cell carcinoma (BSQCC) of the lung is a very rare subtype of squamous cell carcinoma (SCC). There have been no reported cases of SIADH developing concurrently with this tumor.

\section{Case Report}

A 68-year-old Caucasian female sustained a fracture of the

\footnotetext{
Manuscript submitted November 6, 2017, accepted November 16, 2017

aAdvocate Illinois Masonic Medical Center, 836 W Wellington Ave, Chicago, IL, USA

${ }^{\mathrm{b}}$ Corresponding Author: Ashraf Abugroun, Advocate Illinois Masonic Medical Center, 836 W Wellington Ave, Chicago, IL 60657, USA.

Email: ashraf.abugroun@advocatehealth.com
}

right humeral neck following a mechanical fall. She was scheduled for elective surgical fixation. Her past medical history was significant for 50 pack-year smoking history, chronic obstructive pulmonary disease (COPD), diabetes mellitus and hypertension. Pre-operative chest X-ray revealed an abnormal shadow of $4.1 \mathrm{~cm}$ on the left lung. Chest computer tomography (CT) scan revealed a $3.6 \mathrm{~cm}$ soft tissue mass in the anterior lingula (Fig. 1). Few days later, the patient presented to the emergency department with complaints of nausea, vomiting, diarrhea, weakness and dizziness. Laboratory workup showed sodium level $115 \mathrm{mmol} / \mathrm{L}$, serum osmolality $248 \mathrm{mOsm} / \mathrm{kg}$, urine sodium level $106 \mathrm{mmol} / \mathrm{L}$, urine osmolality $554 \mathrm{mOsm} /$ $\mathrm{kg}$, and serum cortisol level $31 \mu \mathrm{g} / \mathrm{dL}$ (normal: 3.4 - 22.5). The patient had normal thyroid-stimulating hormone (TSH), blood urea nitrogen (BUN) and creatinine. Random blood glucose was $150 \mathrm{mg} / \mathrm{dL}$. Serum uric acid was $3.2 \mathrm{mg} / \mathrm{dL}$ (normal 2.6 - 5.9). The hyponatremia was initially felt to be due to volume depletion in setting of decreased oral intake, use of hydrochlorothiazide, vomiting and diarrhea. However, her serum sodium $(\mathrm{Na})$ level did not improve with volume repletion with normal saline but decreased even further to $114 \mathrm{mmol} / \mathrm{L}$. Normal saline infusion was discontinued and fluid restriction was implemented. The serum Na level remained low despite fluid restriction and use of sodium chloride tablets and furosemide. Subsequently the patient received one dose of tolvaptan and her serum Na level increased to $125 \mathrm{mmol} / \mathrm{L}$. Further man-

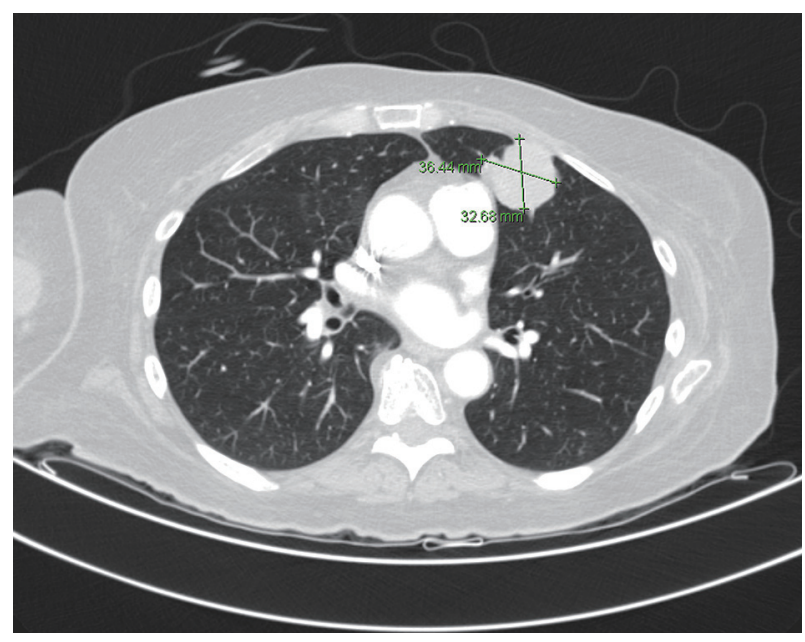

Figure 1. CT scan of the chest shows left hilar mass measuring $4 \mathrm{~cm}$. 


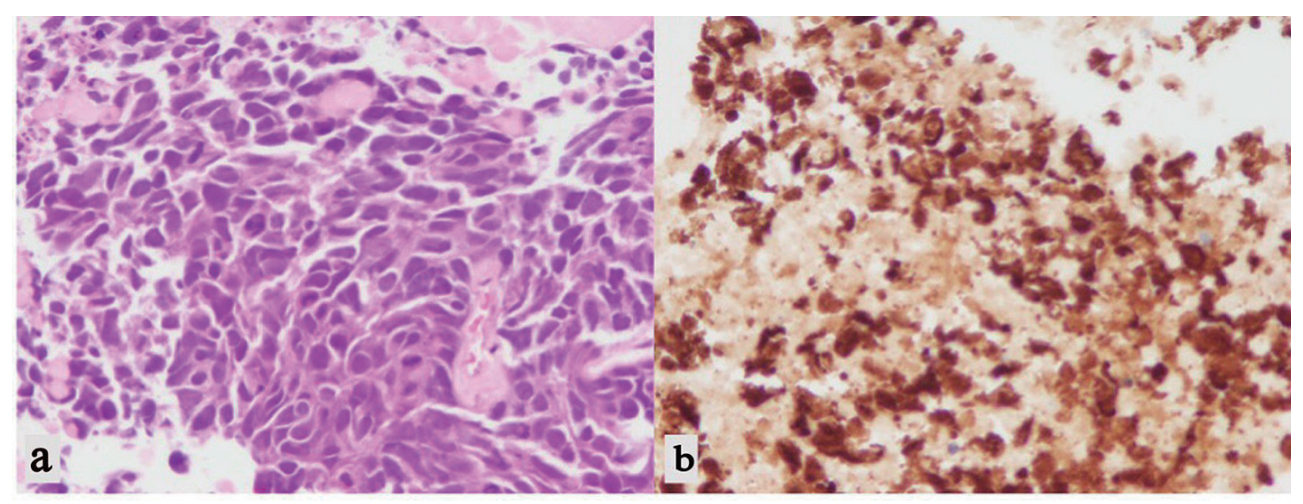

Figure 2. (a) H\&E stain of lung biopsy showing small basophilic cells with a high nuclear to cytoplasmic ratio resembling small cell carcinoma. (b) Positive immunohistochemical stain for cytokeratin 5/6 supporting squamous derivation.

agement included continuing tolvaptan and oral sodium tablets and furosemide and gradual correction of $\mathrm{Na}$ level. Later lung biopsy was done and results showed small basophilic cells with a high nuclear to cytoplasmic ratio resembling small cell carcinoma (Fig. 2). However, immunohistochemical studies showed positivity for cytokeratin $5 / 6$, p40, and CD56. TTF1 , chromogranin, synaptophysin, and neuron specific enolase were negative. A final diagnosis of BSQCC was made. The patient had brain magnetic resonance imaging (MRI) which showed no evidence of metastasis. The patient was not a candidate for surgical resection of the lung tumor due to underlying comorbidity and COPD. She was scheduled for outpatient follow-up and palliative care.

\section{Discussion}

According to the WHO classification of lung tumors, BSQCC is classified as a subtype of SCC [6]. Common location of the tumor is proximal bronchi [7]. The tumor can present as a solitary lesion, or admixed with other types of NSCLC [8]. A multi-centric basaloid carcinoma of lung was also reported [9]. BSQCC has histological and cytological similarities with SCC and large cell neuroendocrine cancer; however, BSQCC has a unique immunostaining pattern that is essential for its diagnosis [10]. BSQCC commonly presents at age above 60 , in few cases it was reported at young age $[11,12]$. The tumor has a strong association with tobacco smoking [13]. The tumor has a characteristic rapid growth rate and clinical progression as well as poor prognosis [7]. Treatments of choice include both surgical resection and adjuvant chemotherapy.

Common etiologies of SIADH include various malignancies particularly small cell lung cancer, neurological diseases, and a variety of medications that induce secretion of the hormone [14]. SIADH in non-small lung cancer is extremely rare. From our review, there have been no reported cases of BSQCC developing concurrently with SIADH. Diagnostic criteria for SIAHD include hyponatremia with hypo-osmolality and continued renal loss of $\mathrm{Na}$ causing relatively higher urinary osmolality in the presence of normal kidney, suprarenal and thyroid function and absence of evidence of fluid volume depletion [15]. Other laboratory findings include low urea and uric acid levels and lower anion gap with nearly normal total carbon dioxide $\left(\mathrm{CO}_{2}\right)$ and serum potassium, despite dilution [16]. Treatment options of SIADH include treating the underlying condition, fluid restriction and in severe cases, administration of intravenous hypertonic saline and/or furosemide therapy. V2 vasopressin receptor antagonists, conivaptan and tolvaptan, have emerged as effective and safe agents for treating SI$\mathrm{ADH}$ associated hyponatremia. Careful monitoring of $\mathrm{Na}$ level is essential, to ovoid higher correction rates which can lead to osmotic demyelination syndrome $[17,18]$.

No other explanation for hyponatremia was identified in our patient. Her laboratory findings including a hyponatremia, increased urine osmolality with worsening of serum osmolality upon administration of IV normal saline and dramatic response to tolvaptan reflect a typical picture of SIADH. In addition, she had normal brain MRI excluding brain metastasis as a cause for SIADH.

At present, therapy for BSQCC of various organs follows guidelines for conventional therapy for SCC. BSQCC of the larynx has a historically worse prognosis compared to conventional SCC with high rates of nodal metastases and distant metastases [19]. Genetic alterations have been shown to be more prevalent in esophageal BSQCC when compared to SCC. This has led to identification of molecular targets for therapy including a common epidermal growth factor receptor (EGFR) mutation in approximately half of patients with esophageal BSQCC [20]. Established research has revealed that cetuximab, a monoclonal antibody targeting EGFR, has improved overall survival in patients with head and neck SCC. Due to its late presentation and difficulty with diagnosis, more research and further experience with this condition would be necessary to see if patients with BSQCC would benefit similarly from further attempts at targeted therapy.

\section{Conclusion}

BSQCC is a subtype of SCC that has a characteristic rapid growth rate and clinical progression as well as poor prognosis. There have been no reported cases of this tumor developing concurrently with SIADH. Further investigation of such association will help in better understanding the mechanism of 
SIADH in lung cancer.

\section{References}

1. Schwartz WB, Bennett W, Curelop S, Bartter FC. A syndrome of renal sodium loss and hyponatremia probably resulting from inappropriate secretion of antidiuretic hormone. Am J Med. 1957;23(4):529-542.

2. Katsuragi N, Shiraishi Y, Nakajima Y, Kurai M, Takahashi N, Tanaka S. [Squamous cell bronchogenic carcinoma with syndrome of inappropriate secretion of antidiuretic hormone]. Kyobu Geka. 2004;57(9):847-850.

3. Seki K, Segawa M, Kusajima Y, Saito K. [Syndrome of inappropriate secretion of antidiuretic hormone associated with resection of pulmonary squamous cell carcinoma]. Kyobu Geka. 2010;63(2):133-137.

4. Higashihara K, Kimbara Y, Suzuki Y, Kawate E, Takahashi H. Severe hyponatremia due to inappropriate secretion of antidiuretic hormone following pleurodesis. Intern Med. 2009;48(12):1069-1071.

5. Oh HJ, Lee MJ, Jang SJ, Shin DH, Kang SW. Syndrome of inappropriate antidiuretic hormone secretion in a patient with large cell neuroendocrine carcinoma. Yonsei Med J. 2012;53(3):667-669.

6. Travis WD, Brambilla E, Nicholson AG, Yatabe Y, Austin JHM, Beasley MB, Chirieac LR, et al. The 2015 World Health Organization classification of lung tumors: impact of genetic, clinical and radiologic advances since the 2004 classification. J Thorac Oncol. 2015;10(9):12431260.

7. Wang LC, Wang L, Kwauk S, Woo JA, Wu LQ, Zhu H, Zhan LZ, et al. Analysis on the clinical features of 22 basaloid squamous cell carcinoma of the lung. J Cardiothorac Surg. 2011;6:10.

8. Sawada T, Machino R, Takeji M, Kitou K. [Adenocarcinoma and basaloid squamous cell carcinoma in the same lung lobe]. Kyobu Geka. 2014;67(3):198-201.

9. Bhagavathi S, Chang CH. Multicentric basaloid carcino- ma of lung clinically mimicking metastatic carcinoma: a case report. Int J Surg Pathol. 2009;17(1):68-71.

10. Crapanzano JP, Loukeris K, Borczuk AC, Saqi A. Cytological, histological, and immunohistochemical findings of pulmonary carcinomas with basaloid features. Diagn Cytopathol. 2011;39(2):92-100.

11. Cakir E, Demirag F, Ucoluk GO, Kaya S, Memis L. Basaloid squamous cell carcinoma of the lung: a rare tumour with a rare clinical presentation. Lung Cancer. 2007;57(1):109-111.

12. Nagakawa $H$, Hiroshima $K$, Takiguchi $Y$, Yatomi M, Takahashi Y, Mikami M, Nakatani Y, et al. Basaloid squamous-cell carcinoma of the lung in a young woman. Int J Clin Oncol. 2006;11(1):66-68.

13. Moro-Sibilot D, Lantuejoul S, Diab S, Moulai N, Aubert A, Timsit JF, Brambilla C, et al. Lung carcinomas with a basaloid pattern: a study of 90 cases focusing on their poor prognosis. Eur Respir J. 2008;31(4):854-859.

14. Baylis PH. The syndrome of inappropriate antidiuretic hormone secretion. Int $\mathrm{J}$ Biochem Cell Biol. 2003;35(11):1495-1499.

15. Sorensen JB, Andersen MK, Hansen HH. Syndrome of inappropriate secretion of antidiuretic hormone (SIADH) in malignant disease. J Intern Med. 1995;238(2):97-110.

16. Decaux G, Musch W. Clinical laboratory evaluation of the syndrome of inappropriate secretion of antidiuretic hormone. Clin J Am Soc Nephrol. 2008;3(4):1175-1184.

17. Gross P. Clinical management of SIADH. Ther Adv Endocrinol Metab. 2012;3(2):61-73.

18. Berl T, Quittnat-Pelletier F, Verbalis JG, Schrier RW, Bichet DG, Ouyang J, Czerwiec FS. Oral tolvaptan is safe and effective in chronic hyponatremia. J Am Soc Nephrol. 2010;21(4):705-712.

19. Thompson LD. Laryngeal dysplasia, squamous cell carcinoma, and variants. Surg Pathol Clin. 2017;10(1):15-33.

20. Saito T, Mitomi H, Yao T. Molecular pathology and potential therapeutic targets in esophageal basaloid squamous cell carcinoma. Int J Clin Exp Pathol. 2015;8(3):22672273. 